\title{
Fermented Miso with Adzuki Beans or Black Soybeans Decreases Lipid Peroxidation and Serum Cholesterol in Mice fed a High-Fat Diet
}

\author{
Shan $\mathrm{Wu}^{1,2}$, Shuo Feng ${ }^{1,2}$, ZhaoHong $\mathrm{Ci}^{1}$, Chengyu Jiang ${ }^{1}$, Yang $\mathrm{Cui}^{1}$, Yuki Sasaki ${ }^{1}$, Yukina Ota $^{1}$, \\ Michiyuki Kojima,** \\ ${ }^{1}$ Department of Food Production Science, Obihiro University of Agriculture and Veterinary Medicine, 11, Nishi-2-sen, Inada-machi, \\ Obihiro, Hokkaido 080-8555, Japan \\ ${ }^{2}$ United Graduate School of Agricultural Sciences, Iwate University, 3-18-8, Ueda, Morioka, Iwate 020-8550, Japan \\ *Corresponding author: kojima@obihiro.ac.jp
}

Received February 02, 2015; Revised February 26, 2015; Accepted March 01, 2015

\begin{abstract}
The seed coat extracts of adzuki beans and black soybeans have high antioxidant properties, suggesting health-promoting effects. However, there are few data on the activity of fermented adzuki beans or black soybeans in vivo. This study examined the effects of adzuki beans and black soybeans in mice fed a high-fat diet. Adzuki beans and black soybeans were fermented with soybeans and rice koji for 6 months (miso) and compared with similarly fermented soybeans. Adzuki beans and black soybeans demonstrated higher antioxidant activity compared to soybeans, as evidenced by the 2,2-diphenyl-1-picrylhydrazyl (DPPH) assay. In the in vivo experiments, mice were fed for 5 weeks with a high-fat diet supplemented or not with $10 \%$ adzuki bean miso, 10\% black soybean miso, or $10 \%$ soybean miso. Dietary supplementation with adzuki beans and black soybeans significantly decreased serum aspartate transaminase (58.6\% and 62.6\%, respectively) and lipid peroxidation in the liver (42.8\% and $40.8 \%$, respectively) compared to the soybean control group. Furthermore, mice receiving adzuki beans demonstrated a significant decrease in serum cholesterol (31.0\%) and increase in fecal bile acid content (40.0\%) compared to the soybean-fed mice. These results indicate that dietary supplementation with adzuki beans and black soybeans characterized with high antioxidant activity may exert health beneficiary effects such as liver protection and reduction of total cholesterol.
\end{abstract}

Keywords: fermentation, adzuki beans, black soybeans, antioxidant activity, cholesterol

Cite This Article: Shan Wu, Shuo Feng, ZhaoHong Ci, Chengyu Jiang, Yang Cui, Yuki Sasaki, Yukina Ota, and Michiyuki Kojima, "Fermented Miso with Adzuki Beans or Black Soybeans Decreases Lipid Peroxidation and Serum Cholesterol in Mice fed a High-Fat Diet.” Journal of Food and Nutrition Research, vol. 3, no. 3 (2015): 131-137. doi: 10.12691/jfnr-3-3-1.

\section{Introduction}

Lifestyle diseases or diseases of longevity are related to an increase in life span in the modern world; they include Alzheimer's disease, arthritis, atherosclerosis, asthma, cancer, chronic liver disease, type 2 diabetes, metabolic syndrome, and obesity [1]. In Japan, westernization has led to an increase of lifestyle diseases. In 2011, the National Health and Nutrition Examination Survey of the Ministry of Health, Labor, and Welfare indicated that meat consumption in Japan increased by 9\% since 2001 (the average daily consumption of meat was $80.7 \mathrm{~g}$ ) [2]. As intake of meat increases, blood cholesterol increases due to excess of cholesterol intake [3]. Chijimatsu et al. fed high cholesterol diet to rats leading to the increase in blood cholesterol in these rats [4].

Active oxygen and free radicals are strong oxidizing agents that are naturally produced in small amounts during normal metabolic activities. The level of reactive oxygen species (ROS) can be transiently increased by air pollutants, smoking, poison, and other adverse factors. Excessive concentrations of ROS can increase lipid peroxidation, resulting in biomembrane and cellular damage, trigger inflammation, and cause organ and tissue dysfunction [5]. Oxidative damage can accumulate during the life cycle and lead to many age-related diseases, including cancer, cardiovascular diseases, and neurological disorders [6-10]. Antioxidants such as polyphenols ingested exogenously in diet can remove excess free radicals [11]. Nakagawa concluded that drinking green tea, which is rich in polyphenols (including epigallocatechin gallate and catechin) contributes to high plasma antioxidant capacity in humans [12].

Adzuki beans, a major product of Tokachi Hokkaido, Japan, have long been cultivated throughout East Asia, and are mainly used in Japanese sweets or fermented products such as bean pastes [13]. In Hokkaido, the production volume of adzuki beans in 2013 was 63,700 tons, which constituted $94 \%$ of total adzuki bean production in Japan [14]. Adzuki bean is very rich in 
polyphenols [15], specifically proanthocyanidins [16] and catechins glucosides [17]. A previous study has indicated that adzuki beans contain polyphenols that have antioxidant effects as well liver protective activity [5]. Nakamura et al. [18] have also found that fermented adzuki bean paste treated with three enzymes ( $\alpha$-amylase, protease, and amyloglucosidase) extracted from Bacillus subtilis and Aspergillus niger and fermented for 4-5 days decreased serum non-high-density lipoprotein (non-HDL) in rats fed a cholesterol-free diet, whereas the unfermented adzuki paste increased non-HDL levels [18]. Adzuki bean paste and its enzyme-treated products have been observed to reduce serum cholesterol in rats $[19,20]$. This may have resulted from decrease in absorption and metabolism of dietary cholesterol or suppression of cholesterol and bile acid synthesis in the liver [21].

Black soybeans are another major produce in Tokachi, Hokkaido, and are widely used in sweets, soy sauce, and beverages. Several studies have found that the seed coat of black soybeans contains anthocyanins, which have high antioxidant activity [22,23]. The protective function of black soybean against CCl4 (a strong oxidant)-induced acute and chronic liver damage was revealed in vivo [24].

Although a number of studies have previously reported that the seed coat extract of adzuki beans and black soybeans have high antioxidant activity [5,22,23], there has been almost no research on the in vivo effects of fermented adzuki beans or black soybeans on antioxidant activity. In this study, we investigated the effect of fermented products (miso) mixed with adzuki beans, black soybeans, and soybeans on the antioxidant activity, serum cholesterol level, and liver function of mice fed a high-fat diet.

\section{Materials and Methods}

\subsection{Production of Miso}

Fermented products (miso), adzuki beans, black soybeans, and soybeans (production date, 2011, expiration date, 2013.11) were obtained from Hosokawa Seian Co. Ltd. (Tokachi, Japan) and rice-koji salt was purchased from the Salt Industry Center (Japan). As a control, common soybean miso (M) was prepared as follows. Raw soybeans (2.5 kg yellow hilum soybeans) were soaked in water (beans/distilled water $=1 / 3(\mathrm{w} / \mathrm{w})$ ), placed in a $1-\mathrm{L}$ beaker, and autoclaved (KT-3045, ALP Co., Ltd., Japan) for $20 \mathrm{~min}$ at $110^{\circ} \mathrm{C}$. Then, $5.68 \mathrm{~kg}$ soybean paste, $2.5 \mathrm{~kg}$ rice-koji, $1.0 \mathrm{~kg}$ salt, $420 \mathrm{~mL}$ seed water, and $400 \mathrm{~g}$ seed miso were mixed with a ladies mixer (KN1500, Taisho electric MFG. Co., Ltd., Japan). Adzuki bean-soybean miso (AM) and black soybean-soybean miso (BSM) were prepared as described for $\mathrm{M}$, but using different proportions: $1.25 \mathrm{~kg}$ adzuki beans (Vigna angularis (Willd.)) and $1.25 \mathrm{~kg}$ soybeans were used for AM, and $1.25 \mathrm{~kg}$ black soybeans (Glycine max) and $1.25 \mathrm{~kg}$ soybeans were used for BSM. The amount of steamed beans and other components is shown in Table 1. Each paste (M, AM, BSM) was packed (10 kg) in pickle barrels (Shinkigosei Co., Ltd. Japan) and fermented at $25-30^{\circ} \mathrm{C}$ for 180 days. The content of each container was mixed thoroughly once a month for 30 min using a ladies mixer (KN1500, Taisho electric MFG. Co., Ltd., Japan). The products were sampled for analysis before fermentation ( 0 time), and after 3 and 6 months of fermentation. A part of 6 month-fermented sample was freeze-dried and used as a dietary supplement in animal experiments.

Table 1. Proportions of soybeans, rice-koji, adzuki beans, black soybeans, salt, and seed miso in miso production

\begin{tabular}{|c|c|c|c|c|c|c|}
\hline & \multicolumn{2}{|c|}{$\mathrm{M}$} & \multicolumn{2}{|c|}{ AM } & \multicolumn{2}{|c|}{ BSM } \\
\hline & g & $\%$ & g & $\%$ & g & $\%$ \\
\hline Steamed soybeans & 5680 & 56.8 & 2840 & 28.4 & 2840 & 28.4 \\
\hline Steamed adzuki beans & - & - & 3260 & 32.6 & - & - \\
\hline Steamed black soybeans & - & - & - & - & 2970 & 29.7 \\
\hline Rice-koji & 2500 & 25.0 & 2500 & 25.0 & 2500 & 25.0 \\
\hline Salt & 1000 & 10.0 & 1000 & 10.0 & 1000 & 10.0 \\
\hline Seed water & 420 & 4.2 & - & - & 290 & 2.9 \\
\hline Seed miso & 400 & 4.0 & 400 & 4.0 & 400 & 4.0 \\
\hline Total & 10000 & 100.0 & 10000 & 100.0 & 10000 & 100.0 \\
\hline
\end{tabular}

Abbreviations: M, soybean miso; AM, adzuki bean-soybean miso; BSM, black soybean-soybean miso. Water content in each miso was 36\% (water content $=($ steamed beans - dry beans + seed water $) / 10000 \times 100)$.

\subsection{Physicochemical Properties and Antioxidant Activity}

Samples (5 g) were extracted with $10 \mathrm{ml}$ distilled water, and centrifuged three times. Soluble solids were measured in water extracts using digital pocket refractometer (PALPatissier; Atago Co., Ltd.), and L-glutamic acid content was determined using the L-glutamic acid assay kit II (Yamasa Corporation Co., Ltd. Japan). The surface color of 6 month-fermented miso was measured using a Chroma Meter (MINOLTA CR-200, Japan) and color intensity was quantified using $L^{*} a^{*} b^{*}$ scales of the color space CIE LAB [25]. Values of $\mathrm{L}^{*}, \mathrm{a}^{*}$ and $\mathrm{b}^{*}$ were measured, and color intensity $\mathrm{C}^{*}$ was calculated according to

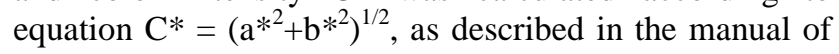
the Chroma Meter. The data were expressed as the mean of 20 measurements.

Each miso sample was extracted with $80 \%$ ethanol and $70 \%$ acetone three times, respectively; the final volume of the extract was $60 \mathrm{~mL}$. Extract of each miso was used to measure Total phenolic content (TPC) and antioxidant activity.

TPC was determined using the Folin-Ciocalteau method [26] with slight modifications. Miso extracts (100 $\mu \mathrm{L}$ ) were mixed with $300 \mu \mathrm{L}$ of distilled water, $400 \mu \mathrm{L}$ of Folin-Ciocalteu reagent (previously diluted 2-fold with distilled water) and $400 \mu \mathrm{L}$ of $\mathrm{Na}_{2} \mathrm{CO}_{3}(100 \mathrm{~g} \mathrm{~L}-1)$, and allowed to stand at $30^{\circ} \mathrm{C}$ for $30 \mathrm{~min}$. The absorbance was measured at $760 \mathrm{~nm}$ and expressed as mg Gallic acid (1g $\left.\mathrm{L}^{-1}\right)$. The linearity range of the calibration curve was $0-$ $125 \mu \mathrm{g}(\mathrm{r}=0.998)$.

Antioxidant activity was assessed using the 1,1Diphenyl-2-picryl-hydrazyl (DPPH) assay [27]. Miso extracts $(150 \mu \mathrm{L})$ were incubated with the same volume of $2 \mathrm{mM}$ DPPH in ethanol in the dark for $15 \mathrm{~min}$, and the decrease in absorbance at $517 \mathrm{~nm}$ was measured using a 96-well microplate reader(MTP300, Corona electric Co. Ltd. Japan). Standard curves were constructed using 
Trolox standards (0-30 nM), and antioxidant activity of the extracts was expressed in Trolox equivalents (nM).

\subsection{Animals and Diets}

Male ddY mice (7 weeks old; Japan SLC, Inc. Shizuoka, Japan) were housed in plastic cages in an animal room maintained at a 12-h light-dark cycle (light period, 8:00 to 20:00) at a constant temperature of $23 \pm$ $2^{\circ} \mathrm{C}$ and relative humidity of $60 \pm 5 \%$. Mice were randomly assigned to four groups $(\mathrm{n}=5)$ and fed a high-fat (HF) diet for 2 weeks. Then, the control group was fed HF diet supplemented with $10 \%$ normal diet (HF group), and the other groups received HF diet supplemented with $10 \%$ M (M-HF group), 10\% AM (AM-HF group), or 10\% BSM (BSM-HF group), respectively (Table 2).

Table 2. Food intake, body weight, fecal weight, and organ weight of mice fed high-fat diet supplemented with miso

\begin{tabular}{ccccccccccccccc}
\hline & \multicolumn{3}{c}{ HF } & \multicolumn{3}{c}{ M-HF } & \multicolumn{3}{c}{ AM-HF } \\
\hline Food intake (g/mouse/day) & 5.94 & \pm & 0.26 & 6.28 & \pm & 0.47 & 6.71 & \pm & 0.53 & 5.76 & \pm & 0.25 \\
Final Body weight (g/mouse) & 47.49 & \pm & 1.96 & 45.10 & \pm & 1.35 & 44.75 & \pm & 1.79 & 45.21 & \pm & 1.66 \\
Fecal weight (g/mouse/day) & 1.04 & \pm & 0.05 & 0.98 & \pm & 0.05 & 1.11 & \pm & 0.18 & 0.94 & \pm & 0.06 \\
Liver weight (g/mouse) & 1.89 & \pm & 0.08 & 1.84 & \pm & 0.09 & 1.54 & \pm & $0.08^{*}$ & 1.54 & \pm & $0.04 *$ \\
Kidney weight (g/mouse) & 0.79 & \pm & 0.03 & 0.83 & \pm & 0.04 & 0.80 & \pm & 0.03 & 0.764 & \pm & 0.04 \\
\hline
\end{tabular}

Abbreviation: HF, high-fat diet supplemented with 10\% normal diet; M-HF, HF diet supplemented with 10\% soybean miso; AM, HF diet

supplemented with $10 \%$ adzuki bean-soybean miso; BSM, HF diet supplemented with $10 \%$ black soybean-soybean miso; values are the means \pm standard error $(\mathrm{n}=5)$. * indicates significant difference with $\mathrm{HF}(\mathrm{p}<0.05)$.

The mice were allowed free access to food and water, and their intake was recorded. After 5 weeks, the final body weight and fecal weight were measured (Table 2). On the final day of the experiment, mice were fasted overnight, anesthetized with nembutal injection $(0.75 \mu \mathrm{L} / \mathrm{g}$ body weight), and laparotomy was performed. Blood was collected from the heart, quickly mixed with EDTA-2Na as an anticoagulant, and separated by centrifugation at $1,000 \times \mathrm{g}$ for $30 \mathrm{~min}$. The livers and kidneys were collected, weighted, quickly frozen in liquid nitrogen, and stored at $-20^{\circ} \mathrm{C}$ until analysis.

The handling of experimental animals was performed according to the Guide for the care and use of laboratory animals [28] and the regulations of the National University Corporation Obihiro University of Agriculture and Veterinary Medicine for animal experiments. The experimental design was approved by the Animal Experiment Committee of Obihiro University of Agriculture and Veterinary Medicine, and it adhered to the standard principles described in the Guide for the Care and Use of Laboratory Animals [29].

\subsection{Analysis of Sera, Organs, and Fecal Matter}

Neutral lipids, free fatty acids, phospholipids, total cholesterol, LDL cholesterol, alanine aminotransaminase (ALT), aspartate transaminase (AST), and lactate dehydrogenase (LDH) in serum were measured using a TDX Analyzer (ABBOTT JAPAN CO., LTD., Tokyo, Japan).

Lipid peroxidation in serum was assessed by measuring thiobarbituric acid reactive substances (TBARS). For this, $400 \mu \mathrm{L}$ of $8.1 \%$ SDS solution was added to $100 \mathrm{mg}$ liver, and then $300 \mu \mathrm{L} 20 \%$ acetic acid buffer (pH 3.5) and 500 $\mu \mathrm{L}$ of distilled water were added. The mixture was homogenized with a Teflon homogenizer and $600 \mu \mathrm{L}$ was transferred to a clean dry glass tube containing equal volume of $25 \mathrm{ppm}$ aqueous solutions of copper(II) sulfate, and the reaction mixture was incubated for $1 \mathrm{~h}$ at $37^{\circ} \mathrm{C}$. After the reaction, $950 \mu \mathrm{L}$ was removed into a capped test tube, where $25 \mu \mathrm{L} 0.8 \%$ BHT acetic acid and $750 \mu \mathrm{L}$ $0.8 \%$ TBA were added. After $1 \mathrm{~h}$ on ice, the reaction was incubated for $1 \mathrm{~h}$ at $100^{\circ} \mathrm{C}$ in a block heater, cooled in running water, and $500 \mu \mathrm{L}$ of distilled water and $2.5 \mathrm{~mL}$ of n-butanol:pyridine (15:1) were added with vigorous

stirring, centrifuged at $1,500 \times \mathrm{g}$ for $10 \mathrm{~min}$, and the absorbance at $532 \mathrm{~nm}$ was measured. Lipid peroxidation was calculated as the amount of 1,1,3,3tetraethoxypropane (TEP) [30].

The freeze-dried fecal masses were degreased, redissolved in isopropanol, and analyzed for cholesterol content using the Wako cholesterol-E Test kit (Wako Pure Chemical Industries, Ltd., Osaka, Japan).

Bile acid content was measured by extracting $100 \mathrm{mg}$ feces with three-fold amount of distilled water for $20 \mathrm{~min}$ by sonication; the extract was centrifuged at $1,000 \times \mathrm{g}$, and supernatant was collected. The procedure was performed three times, supernatants were combined, and bile acid content was measured using the Total Bile Acid Test Wako kit (Wako) and expressed as the amount of cholic acid.

\subsection{Statistical Analyses}

The data are presented as the mean \pm standard error. The significance of differences was analyzed by ANOVA and Tukey`s studentized range (HSD) test (SAS 9.3 software, SAS Institute Inc.). The level of significance was set at $p<0.05$.

\section{Results and Discussion}

\subsection{Physicochemical Properties, Antioxidant Activity, and Sensory Evaluation of Miso}

Miso fermentation includes the hydrolysis of protein to amino acids and starch to glucose [31]. We evaluated miso fermentation by the content of L-glutamic acid ( $\mathrm{mg} / \mathrm{g}$ miso: $\mathrm{M}_{0}=0.8 \pm 0.1, \mathrm{M}_{6}=1.1 \pm 0.1 ; \mathrm{AM}_{0}=0.7 \pm 0.1, \mathrm{AM}_{6}=1.0$ $\pm 0.3 ; \mathrm{BSM}_{0}=0.8 \pm 0.1, \mathrm{BSM}_{6}=1.0 \pm 0.4$;) and soluble solids (Brix\%: $M_{0}=6.2, M_{6}=8.3$; the same for $A M$ and BSM), which showed an increase with the time of fermentation. No significant differences were observed among the samples, suggesting that in adzuki beansoybean miso and black soybean-soybean miso, the fermentation process, i.e., protein breakdown and starch degradation, was complete.

Color intensity C* refers to the brightness and dullness of sample color according to Art Studio Chalkboard. Color intensity $\mathrm{C}^{*}$ in the samples after 6-month fermentation was: M, $9.05 \pm 0.7$; $\mathrm{AM}, 12.52 \pm 0.8$; and 
BSM, $10.23 \pm 0.6$, indicating that this parameter was significantly higher for AM and BSM compared to M $(p<$ 0.05). The color of AM and BSM was considered vivid, because the seed coats in adzuki beans and black soybeans contain bright red, brown, and purple pigments [32,33] absent in soybeans.

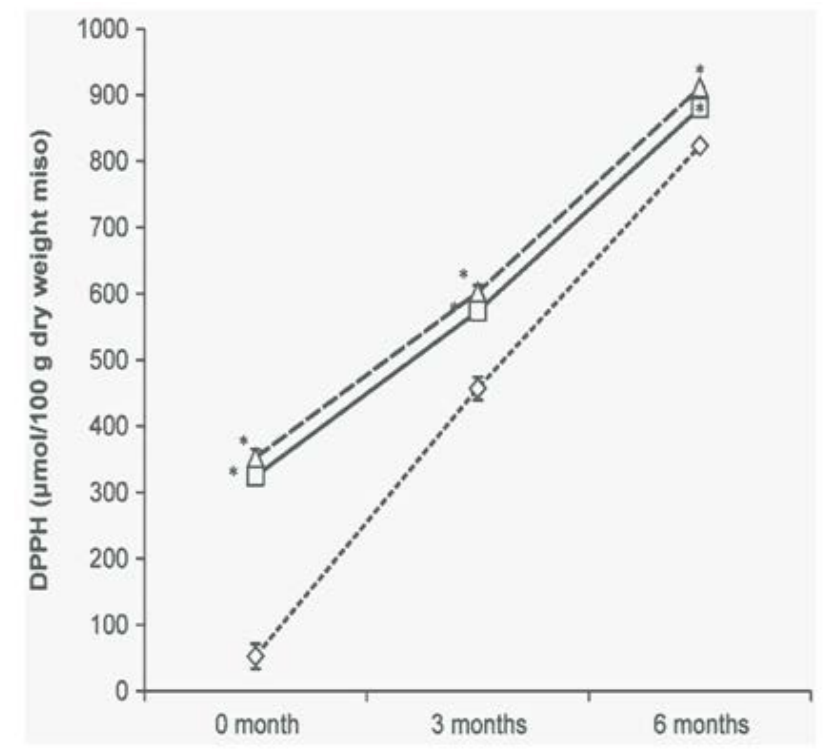

Figure 1. Changes of the DPPH radical-scavenging activity in three types of miso. $\boldsymbol{\Delta}$ black soybean-soybean miso; $\mathbf{D}$ adzuki bean-soybean miso; soybean miso. *indicates significant difference with $\mathrm{M}(\mathrm{p}<0.05)$

In all fermented products, TPC increased with the fermentation time (mg/g miso: $\mathrm{M}_{0}=1.0 \pm 0.1, \mathrm{M}_{6}=9.9 \pm$ $0.0 ; \mathrm{AM}_{0}=1.7 \pm 0.1, \mathrm{AM}_{6}=9.5 \pm 0.1 ; \mathrm{BSM}_{0}=2.1 \pm 0.0$, $\left.\mathrm{BSM}_{6}=11.6 \pm 0.1 ; \mathrm{p}<0.05\right) . \mathrm{DPPH}$ radical scavenging activity in all fermented products increased with the fermentation time, but in BSM and AM, it was significantly higher than that in $\mathrm{M}$ after 6 months ( $\mathrm{p}<$ 0.05) (Figure 1). The increase in DPPH scavenging activity of soybeans is known to occur because of the production of daidzein, genistein, and melanoidins during fermentation [34]. Since half of the beans in AM and BSM samples were soybeans, we determined DPPH increase produced by the fermentation of adzuki beans and black soybeans as 1.57-fold and 1.53-fold, respectively, using the formula: $\left(\mathrm{DPPH}_{\mathrm{AM} 6}-\mathrm{DPPH}_{\mathrm{M} 6} / 2\right) /\left(\mathrm{DPPH}_{\mathrm{AM} 0^{-}}\right.$ $\left.\mathrm{DPPH}_{\mathrm{M} 0} / 2\right)$. Correlation between DPPH radicalscavenging activity and TPC in 3 types of miso was calculated by Pearson correlation (Correlation function, $r$ $=0.908(\mathrm{p}<0.01))$. Takasaki et al. reported that a high positive correlation was observed between the content of the total polyphenols and the DPPH radical-scavenging activity (Correlation function, $r=0.990(p<0.01)$ ) [34]. This result is consistent with the present study. Therefore, we hypothesize that the antioxidant activity of $\mathrm{M}, \mathrm{AM}$, and BSM are closely related to polyphenol.

Friedman ranking test [35] was used to cumulatively evaluate such parameters as color, aroma, taste, and flavor in 6 month-fermented miso samples (score of 1 indicates the best and 3 - the worst). The ranking of color and aroma for AM, BSM, and M was 1, 2, and 3, respectively $(p=0.01)$. No significant difference in taste between the samples was detected, possibly because miso taste is defined by a combination of sweetness, sourness, and umami, which is not easy for the panelists to evaluate. In this study, the taste was analyzed using taste sensors. Higher color intensity C* of AM and BSM explains preferential color ranking of these miso samples compared to $\mathrm{M}$.

\subsection{Effects of AM and BSM on Food Intake and Body, Organ, and Fecal Weight of High- fat Diet-fed mice}

There was no significant difference observed in food intake, and final body, kidney, and fecal weight between the groups (Table 2). However, mice fed with high-fat diet supplemented with AM and BSM demonstrated a decrease in liver weight $(18.5 \%, \mathrm{p}<0.05)$ compared to the control group (HF). There was no significant difference between the $\mathrm{HF}$ and $\mathrm{M}-\mathrm{HF}$ groups.

$\mathrm{Gu}$ et al. [36] have reported that dietary cocoa supplementation of high-fat diet for 10 weeks suppresses the increase of liver weight and ameliorates fatty liver disease symptoms in mice. The addition of adzuki polyphenol extract (APP) to drinking water used at a single dose reduced liver injury, liver weight, peroxide content, and serum AST in 11-week old ddY mice, suggesting that APP exerts hepatoprotective effects [5]. Orihashi [37] has shown that diet supplementation with 1year fermented miso for 6 weeks prevents fatty liver disease in cows. The hepatoprotective effect of miso may depend on the fermentation time and vary with experimental animal spices and feeding period. In our study, dietary AM and BSM reduced liver damage in mice fed a high-fat diet for 5 weeks.

\subsection{Effect of AM and BSM on Serum Lipids, LDH, and ALT in Mice on a High-fat Diet}

Table 3. Serum composition of mice after 5 weeks of dietary treatment (high fat diet:miso = 9:1)

\begin{tabular}{|c|c|c|c|c|c|c|c|c|c|c|c|c|}
\hline \multirow[b]{2}{*}{ Neutral lipids (mg/dL) } & \multicolumn{3}{|c|}{$\mathrm{HF}$} & \multicolumn{3}{|c|}{ M-HF } & \multicolumn{3}{|c|}{ AM-HF } & \multicolumn{3}{|c|}{ BSM-HF } \\
\hline & 50.13 & \pm & 7.18 & 53.76 & \pm & 5.29 & 43.14 & \pm & 5.38 & 42.24 & \pm & 7.66 \\
\hline Free fatty acid (mEq/L) & 406.60 & \pm & 41.86 & 400.80 & \pm & 31.83 & 377.00 & \pm & 45.77 & 362.60 & \pm & 25.87 \\
\hline Phospholipids (mg/dL) & 266.78 & \pm & 20.65 & 276.46 & \pm & 13.91 & 221.60 & \pm & 13.92 & 250.80 & \pm & 16.91 \\
\hline $\mathrm{LDH}(\mathrm{U} / \mathrm{L})$ & 458.80 & \pm & 59.32 & 632.60 & \pm & 80.13 & 513.60 & \pm & 79.04 & 517.00 & \pm & 93.01 \\
\hline $\operatorname{ALT}(\mathrm{U} / \mathrm{L})$ & 52.60 & \pm & 14.71 & 52.00 & \pm & 1.70 & 30.80 & \pm & 4.83 & 22.00 & \pm & 1.76 \\
\hline
\end{tabular}

Abbreviation: HF, high-fat diet supplemented with 10\% normal diet; M-HF, HF diet supplemented with 10\% soybean miso; AM, HF diet

supplemented with $10 \%$ adzuki bean-soybean miso; BSM, HF diet supplemented with $10 \%$ black soybean-soybean miso; LDH, lactate dehydrogenase; ALT, alanine aminotransferase; values are the means \pm standard error $(\mathrm{n}=5)$. * indicates significant difference with HF $(\mathrm{p}<0.05)$.

The analysis of serum lipids, including neutral lipids, that the adzuki bean extract decreases serum triglyceride free fatty acids, and phospholipids indicated that there was no significant difference between the control and other groups (Table 3). Kitano-Okada et al. [38] have shown concentration and improves lipid metabolism in rats fed a normal diet for 4 weeks. However, noodle-added rutin decreased serum free fatty acid content in rats from CLEA 
(Japan) but not from Charles River Laboratories (CRL, USA). It is possible that the differences in animal maintenance between the companies could affect intestinal bacterial population in rats, which may influence experimental results [39]. In our study, the supplementation with AM, BSM, and M did not affect serum lipid content in mice fed a high-fat diet for 5 weeks.

\subsection{Effect of AM and BSM on Serum AST and Hepatic Lipid Peroxidation in Mice on a High-fat Diet}

AM and BSM supplementation reduced serum AST levels by $58.6 \%$ and $62.6 \%$, respectively, compared to HF $(p<0.05$, Figure 2A). Lipid peroxidation in the liver was also decreased in the AM-HF and BSM-HF groups by

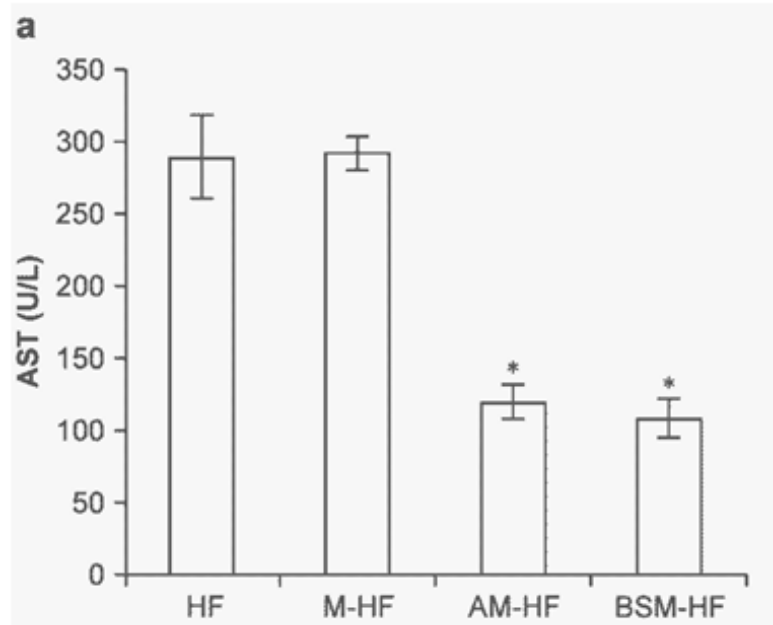

$42.8 \%$ and $40.8 \%$, respectively, compared to the HF group ( $\mathrm{p}<0.05$, Figure 2B). However, no differences were found in these parameters between the $\mathrm{HF}$ and $\mathrm{M}-\mathrm{HF}$ groups.

Liver disease is characterized by elevated concentrations of liver injury markers, including ALT, AST, and c-glutamyl-transferase (GGT) [40]. Here, we observed a decrease in serum AST levels in the AM- and BSM-fed mice compared to the control mice. Black soybeans and sword beans fed to rats on a high-fat diet have been shown to decrease hepatic levels of TBARS [41], which is consistent with our results. Gu et al. [36] have reported that cocoa supplementation decreased serum ALT and hepatic triglyceride levels, and suppressed liver inflammation in high-fat diet-fed mice.

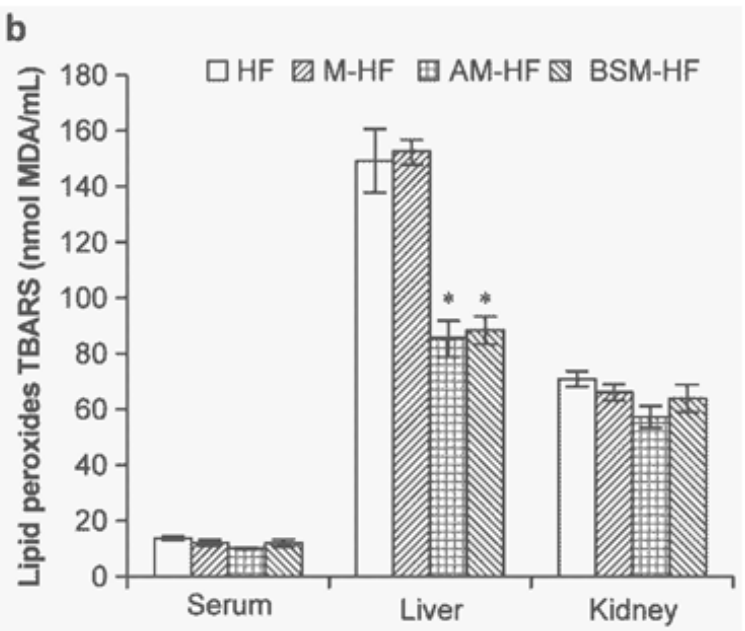

Figure 2. Serum aspartate transaminase (AST; A) and lipid peroxides in internal organs (B) of mice 5 weeks after dietary treatment (high fat diet : miso $=9: 1$ ). HF, high-fat supplemented with $10 \%$ normal diet; M-HF, HF diet supplemented with $10 \%$ soybean miso; AM, HF diet supplemented with $10 \%$ adzuki bean-soybean miso; BSM, HF diet supplemented 10\% black soybean-soybean miso; MDA, malondialdehyde; TBARS, thiobarbituric acid reactive substances. *indicates significant difference compared with $\mathrm{HF}(\mathrm{p}<0.05)$

Our data indicate that in adzuki miso (AM) and black soybean miso (BSM) fermented for 6 months, DPPH scavenging activity was higher compared to soybean miso (M), which correlated with a significant reduction in serum AST and hepatic lipid peroxidation levels in mice on a high-fat diet. However, in some studies, the difference in the in vitro antioxidant activity of fermented extracts did not affect the in vivo parameters [42]; thus, soybeans with high antioxidant activity in vitro did not produce significant effects in vivo $[43,44,45]$. Nishi et al. observed that adzuki cleared free radicals generated by inflammation and suppressed the generation of lipid peroxides resulting in suppressing the inflammation of liver [3].

We suggest that the beneficial effects of AM and BSM supplementation in vivo are underlain by their antioxidant activity (due to the polyphenol content of AM and BSM), such as quenching of free radicals generated by inflammation and suppression of hepatic lipid peroxidation, which resulted in liver protection against high-fat diet.

\subsection{AM Effects on the Levels of Serum Total Cholesterol and Fecal Bile Acids in Mice on a High-fat Diet}

Serum total cholesterol in the AM-HF group was significantly lower (31.0\%, p < 0.05), while fecal bile acid content was significantly higher $(40 \%$, p $<0.05)$ compared to the HF group (Figure 3A). No difference in these parameters was detected between the M-HF, BSM$\mathrm{HF}$, and HF groups. Our data are consistent with the findings of a previous study showing that steamed soybeans and doenjang (steamed soybeans fermented and aged for 10 months) suppressed body weight gain and elevation of hepatic triglyceride and cholesterol levels in Sprague-Dawley rats fed a high-fat (30\%) diet for 8 weeks [46].

In the present study, we found that AM supplementation significantly decreased serum total cholesterol level in mice on a high-fat diet. Our results are in agreement with the data reported by Nishi et al. [3], who showed that the increase in serum cholesterol level in rats fed a high-cholesterol diet was ameliorated by the addition of the ethanol extract of adzuki bean seeds. Nishi et al. reported that extract of adzuki bean seeds had micellar solubility of cholesterol in vitro. They inferred that this might be the effect of polyphenols [3]. Ikeda et al. also reported that polyphenols (A(-)-epicatechin and (-)epigallocatechin mixture and their gallates) contained in green tea had micellar solubility of cholesterol and decreased cholesterol absorption in rats [21]. Han et al. reported that enzyme-resistant fractions of adzuki (Vigna 
angularis) and tebou (Phaseolus vulgaris, var.) beans decreased serum cholesterol in rats through the enhanced levels of hepatic scavenger receptor class B member 1 and cholesterol $7 \alpha$-hydroxylase mRNA [19]. Buhman et al. also demonstrated that feeding psyllium to rats enhanced the level of hepatic cholesterol $7 \alpha$-hydroxylase mRNA as

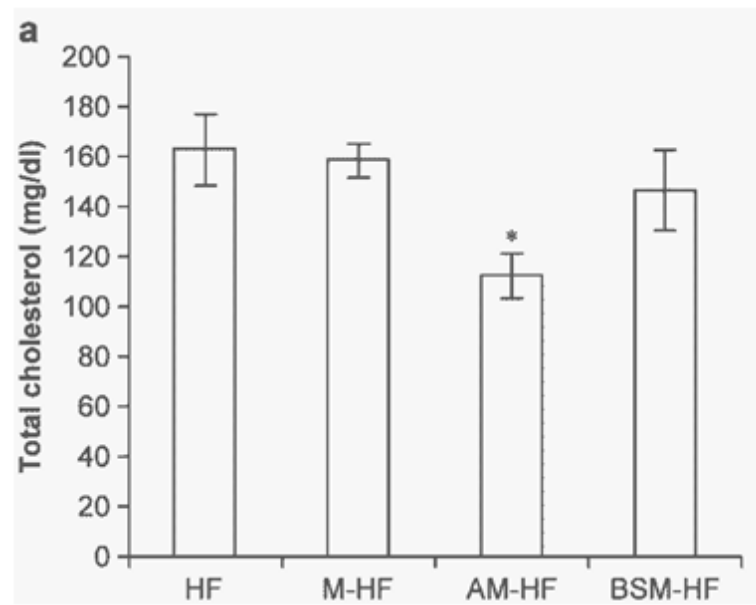

well as fecal bile acid and total steroid excretions [47]. Chijimatsu et al. speculated that the hypocholesterolaemic effects of freshwater clam (Corbicula fluminea) extract might be due to increased fecal neutral sterol, bile acid excretion and hepatic cholesterol 7a-hydroxylase gene expression [4].

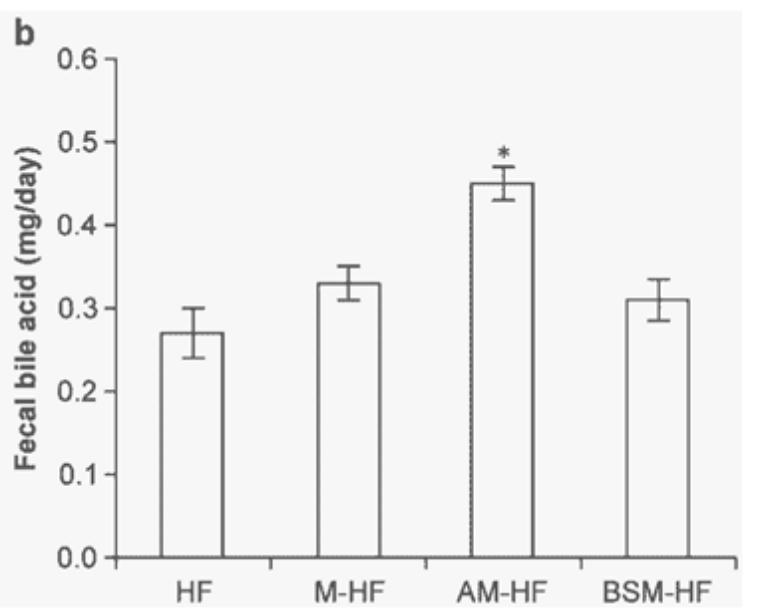

Figure 3. Serum total cholesterol (A) and fecal bile acid (B) in mice fed a high-fat diet supplemented with miso. HF, high-fat diet supplemented with 10\% normal diet; M-HF, HF diet supplemented with 10\% soybean miso; AM, HF diet supplemented with 10\% adzuki bean-soybean miso; BSM, HF diet supplemented with $10 \%$ black soybean-soybean miso; *indicates significant difference with $\mathrm{HF}(\mathrm{p}<0.05)$

Another group has also demonstrated beneficial effects of the fermented adzuki bean paste on serum cholesterol in rats. They showed that diet supplementation with the fermented adzuki paste reduced serum level of non-highdensity lipoprotein (non-HDL) cholesterol in rats, whereas the addition of boiled adzuki paste had no effect [18]. Our results indicate that AM and BSM supplementation exerted significant beneficial effects by the reduction of serum total cholesterol, probably through acceleration of cholesterol conversion into bile acids, as suggested by the increase of bile acid excretion in feces (Figure 3B). We considered that the reduction in blood cholesterol was the action of polyphenols contained in AM. Future studies should focus on the study of the composition of polyphenols contained in the fermented product (AM).

\section{Conclusion}

Our results indicate that the fermented adzuki beanscontaining miso and black soybeans-containing miso exhibit significant antioxidant activity in vitro and demonstrate hepatoprotective effects in vivo, which may be related to their antioxidant components (polyphenols). Our data suggest that dietary supplementation with these food products may exerts more significant beneficiary health effects compared to that of the soybean miso. More studies are required to confirm the mechanisms of healthpromoting activities related to the consumption of fermented adzuki beans and black soybeans.

\section{Acknowledgements}

We acknowledge financial support given by the Obihiro University of Agriculture and Veterinary Medicine, and Iwate University in the completion of the study.

\section{Statement of Competing Interests}

We declare that we do not have any conflict of interest.

\section{References}

[1] Yui, K., Uematsu, H., Muroi, K., Ishii, K., Baba, M., and Osada, K., "Effect of dietary polyphenols from hop (Humulus lupulus L.) pomace on adipose tissue mass, fasting blood glucose, hemoglobin A1c, and plasma monocyte chemotactic protein-1 levels in OLETF rats,” Journal of Oleo Science, 62, 283-292, 2013.

[2] The advance of carnivorous of Japanese [Growing lifestyle-related diseases risk], Nihon Keizai Shimbun, http://www.nikkei.com/article/DGXNASDG06048_W2A201C1C R8000/ 2012/12/6 (in Japanese).

[3] Nishi, S., Yamashita, S., Saito, Y., Maeda, R., and Kojima, M., "Smaller increase in serum cholesterol level in rats fed an ethanol extract of adzuki bean seeds,” Nippon Shokuhin Kagaku Kogaku Kaishi, 53, 380-385, 2006 (in Japanese).

[4] Chijimatsu, T., Umeki, M., Okuda, Y., Yamada, K., Oda, H. and Mochizuki, S., "The fat and protein fractions of freshwater clam (Corbicula fluminea) extract reduce serum cholesterol and enhance bile acid biosynthesis and sterol excretion in hypercholesterolaemic rats fed a high-cholesterol diet.” British Journal of Nutrition, 105, 526-534, 2011.

[5] Yamashita, S., Nishi, S., Saito, Y., Maeda, R. and Kojima, M., "Antioxidative effect and liver protective action of adzuki polyphenol,” Nippon shokuhin kagaku kogaku kaishi, 53, 386-392, 2006 (in Japanese).

[6] Nakayama, T., Kodama, M. and Nagata, C., "Generation of hydrogen peroxide and superoxide anion radical from cigarette smoke.” Gan, 75, 95-98, Feb. 1984.

[7] Halliwel, B. and Gutteridge, J.M.C., Free radicals in biology and medicine. Oxford University Press, 1989, pp. 323-332.

[8] Yoshikawa, T. and Kondo, M., Cellular Membrane: a key to disease processes, Boca Raton, CRC Press, 1993, pp. 271-284.

[9] Yoshikawa., T., "Free radicals and their scavengers in Parkinson`s disease,” European Neurology, 33, 60-68, 1993.

[10] Medvedev, Z.A., "An attempt at a rational classification of theories of ageing,” Biological Reviews, 65, 375-398, Aug. 1990.

[11] Osawa, T., Yoshida, A., Kawakishi, S., Yamashita, K. and Ochi, H., Protective role of dietary antioxidants in oxidative stress. In: 
Cutler, R.G..Packer, L., Bertram, J. and Mori, A. (Eds.) Oxidative Stress and Aging, Birkhauser Verlag, Basel/Switzerland, 1995.

[12] Nakagawa,K., Ninomiya, M., Okubo,T., Aoi, N., Juneja, L., Kim, M., Yamanaka, K., and Miyazawa, T., "Tea Catechin Supplementation Increases Antioxidant Capacity and Prevents Phospholipid Hydroperoxidation in Plasma of Humans.” Journal of Agricultural and Food Chemistry, 47, 3967-3973, 1999.

[13] Hatai, A., "Cooking Characteristics of Adzuki Beans, Vigna angularis," The Japan Society of Cookery Science, 27, 238-242, 1994 (in Japanese).

[14] Ministry of agriculture, forestry and fisheries, Crop yields of beans (dry grain) and buckwheat (by National Agricultural regions and prefectures)-adzuki beans, 2013 annual production crop statistics (Ordinary crops, feed crops, crafts crops), Statistical information, 2013. http://www.maff.go.jp/j/tokei/index.html

[15] Wu, X., Beecher, G.R., Holden, J.M., Haytowitz, D.B., Gebhardt, S.E. and Prior, R.L., "Lipophilic and hydrophilic antioxidant capacities of common foods in the United States," Journal of Agricultural and Food Chemistry, 52, 4026-4037, 2004.

[16] Sato, S., Hori, Y., Yamate, J., Saito, T., Kurasaki, M. and Hatai, A., "Protective effect of dietary azuki bean (Vigna angularis) seed coats against renal interstitial fibrosis of rats induced by cisplatin.” Nutrition., 21, 504-511, 2005.

[17] Kojima, M., Yamashita, S., Nishi, S., Saito, Y., Maeda, R., "Antioxidative Effect and Liver Protective Action of Adzuki Polyphenol.” Nippon Shokuhin Kagaku Kogaku Kaishi, 53, 386392, 2006.

[18] Nakamura, Y., Yabe, K., Shimada, K., Sasaki, K., Han, K., Okada, T., Sekikawa, M., Ohba, K., Ito, N., Horiuchi, K., Kawakami, S., and Fukushima, M., "Effect of Fermented Bean Paste on Serum Lipids in Rats Fed a Cholesterol-Free Diet," Bioscience, Biotechnology, and Biochemistry, 73, 2506-2512, Nov. 2009.

[19] Han, K.H., Fukushima, M., Kato, T., Kojima, M., Ohba, K., Shimada, K., Sekikawa, M. and Nakano, M., "Enzymeresistant fractions of beans lowered serum cholesterol and increased sterol excretions and hepatic mRNA levels in rats." Lipids, 38,919-924, 2003.

[20] Han, K.H., Fukushima, M., Shimizu, K., Kojima, M., Ohba, K., Tanaka, A., Shimada, K., Sekikawa, M. and Nakano, M. "Resistant starches of beans reduce the serum cholesterol concentration in rats." Journal of Nutritional Science and Vitaminology, 49, 281-286, 2003.

[21] Ikeda, I., Imasato, Y., Sasaki, E., Nakayama, M., Nagao, H., Takeo, T., Yayabe, F. and Sugano, M., "Tea catechins decrease micellar solubility and intestinal absorption of cholesterol in rats.” Biochimica et Biophysica Acta, 1127, 141-146, 1992.

[22] Tsuda, T., Watanabe, M. and Ohshima, K., "Antioxidative activity of the anthocyanin pigments cyanidin 3-O- $\beta$-D-glucoside and cyanidin," Journal of Agricultural and Food Chemistry, 42, 24072410, Nov. 1994.

[23] Acquaviva, R., Russo, A., Galvano, F., Galvano, G., Barcellona, M.L., Li Volti, G., and Vanella, A., "Cyanidin and cyanidin 3-O$\beta$-D-glucoside aas DNA cleavage protectors and antioxidants," Cell Biology and Toxicology, 19, 243-252, Aug. 2003.

[24] Hsu, C.K., Chang, C.H., Wang, C.C., "Black Soybeans Show Acute and Chronic Liver Protective Functions Against Ccl4 Induced Liver Damage.” World Academy of Science, Engineering and Technology, 3, 7, 2015.

[25] CIE, Colorimetry (Second Edition), Central Bureau of the Commission International de L'Eclairage, Viena, 1986.

[26] Raki'c, S., Petrovi'c, S., Kuki'c, J., Jadranin, M., Tesevi'c, V. Povrenovi'c, D. and Šiler-Marinković, S., "Influence of thermal treatment on phenolic compounds and antioxidant properties of oak acorn from Serbia.” Food Chemistry, 104, 830-834, 2007.

[27] Blois, M.S., "Antioxidant determinations by the use of a stable free radical," Nature, 181, 1199-1200, Apr. 1958.

[28] Guide for the care and use of laboratory animals. Institute of laboratory animal resources commission on life sciences, National Academy Press, Washington, D.C, 1996.

[29] National Research Council, Guide for the Care and Use of Laboratory Animals. National Academy Press, Washington, 1996.
[30] Kosugi, H., Kojima, T., and Kikugawa, K., "Thiobarbituric acidreactive substances from peroxidized lipids," Lipids, 24, 873-881, Oct. 1989.

[31] Gomyo, N., "Miso science and technology," National Miso Engineering Society, 47, 205, 1999.

[32] Yoshida, K., Sato, H., Ueshima, H., Ishii, N. and Sato, M., "The Extent and Its Source of Variation for Characteristics Related to Seed Quality of Adzuki Beans: II. Variation of seed coat color among growers lots in Hokkaido area," Japan Journal of Crop. Science, 60, 234-240, 1991 (in Japanese).

[33] Yoshida, K., Kameda, K. and Kondo, T., "Studies on anthocyanins of edible legumes," Urakami Foundation Memories, 5, 85-95, 1996 (in Japanese).

[34] Takasaki, S., Kouda, I., Ishikawa, M., Okamoto-kainuma, A. Koizumi, Y. and Fukuda, Y., "Properties of the novel products of miso developed using sesame flour," Journal of Brewing Society of Japan, 105, 749-758, 2010 (in Japanese).

[35] Friedman, M., "A comparison of alternative tests of significance for the problem of m rankings," Annals of Mathematical Statistics, 11, 86-92, 1940.

[36] Gu, Y., Yu, S. and Lambert, J.D., "Dietary cocoa ameliorates obesity-related inflammation in high fat-fed mice," European Journal of Nutrition, 53, 149-158, Feb. 2014.

[37] Orihashi, T., "Research about effect of miso on prevention of fatty liver in cow," Journal of Brewing Society of Japan, 107, 19-24, 2012.

[38] Kitano-Okada, T., Ito, A., Koide. A., Nakamura, Y., Han, K.H., Shimada, K., Sasaki, K., Ohba, K., Sibayama, S. and Fukushima, M., "Anti-obesity role of adzuki bean extract containing polyphenols: in vivo and in vitro effects," Journal of the Science of Food and Agriculture, 92, 2644-2651, Oct. 2012

[39] Yasuda, T., Nakajima, K., Hiwatashi, A., Moroi, C., Sanada, H. and Egashira, Y., "Effect of Rutin in Buckwheat Noodle on Lipid Metabolism in Rats," Food Science and Technology Research, 19, 1011-1018, 2013.

[40] Clark, J., Brancati, F. and Diehl, A., "The prevalence and etiology of elevated aminotransferase levels in the United States," American Journal of Gastroenterology, 98, 960-967, May 2003.

[41] Byun, J.S., Han, Y.S. and Lee, S.S., "The Effects of Yellow Soybean, Black Soybean, and Sword Bean on Lipid Levels and Oxidative Stress in Ovariectomized Rats,” International Journal for Vitamin and Nutrition Research, 80, 97-106, Apr. 2013.

[42] Georgetti, S. R., Vicentini, F. T., Yokoyama, C. Y., Borin, M. F., Spadaro, A. C., Fonseca, M. J., "Enhanced in vitro and in vivo antioxidant activity and mobilization of free phenolic compounds of soybean flour fermented with different $\beta$-glucosidase-producing fungi," Journal of Applied Microbiology, 106, 459-466, Feb. 2009

[43] Matsuo, M. and Takeuchi, T., "Preparation of low salt miso-like fermented seasonings using soy-oncom and okara-oncom (fermented soybeans and okara with Neurospora intermedia) and their antioxidant activity and antimutagenicity," Food Science and Technology Research, 9, 237-241, 2003.

[44] Matsuo, M., "Low-salt O-miso produced from koji fermentation of oncom improves redox state and cholesterolemia in rats more than low-salt soybean-miso," Journal of Nutritional Science and Vitaminology, 50, 362-366, Oct. 2004.

[45] Matsuo, M., "Chemical components, palatability, antioxidant activity and antimutagenicity of oncom miso using a mixture of fermented soybeans and okara with Neurospora intermedia," Journal of Nutritional Science and Vitaminology, 52, 216-222, June 2006.

[46] Kwak, C.S., Park, S.C. and Song, K.Y., "Doenjang, a fermented soybean paste, decreased visceral fat accumulation and adipocyte size in rats fed with high fat diet more effectively than nonfermented soybeans,” Journal of Medicinal Food, 15, 1-9, Jan. 2012.

[47] Buhman, K.K., Furumoto, E.J., Donkin, S.S., and Story, J.A., "Dietary Psyllium Increases Fecal Bile Acid Excretion, Total Steroid Excretion and Bile Acid Biosynthesis in Rats.” Journal of Nutrition, 28, 1199-1203, 1998. 